\title{
Is There a Relationship between Breastfeeding Status and Life Style Changes, Eating Behaviors, Attitudes, and Orthorexia Nervosa tendencies of Mothers? A Web Based Study
}

\author{
Tuba FENERCIOGLU EKEN ${ }^{1}$, Duygu AYHAN BASER ${ }^{2}$, Ismail KASIM ${ }^{1}$, İrfan \\ SENCAN $^{3}$, and Adem ÖZKARA ${ }^{3}$ \\ ${ }^{1}$ Health Science University, Ankara City Hospital \\ ${ }^{2}$ Hacettepe University Faculty of Medicine \\ ${ }^{3}$ Ankara City Hospital
}

November 24, 2020

\begin{abstract}
Objective: It was aimed to compare the breastfeeding status and healthy life style changes, eating behaviors, attitudes, and orthorectic tendencies of mothers. Materials and Methods: All volunteered mothers who have a child between the ages of 0 and 2 were included in this cross-sectional study. 514 individuals were included. Five parted questionnaire and "ORTO-11" test and "Eating Attitude Test" was used. Results: A statistically significant relationship was found between breastfeeding status and working status and professions of mothers. Mothers who did not breastfeed, skipped main meal more frequently, and smoking and occasional alcohol consumption was higher. The mean score of the participants on the ORTO-11 scale was 25.09 \pm 4.80 , EAT-40 scale mean score was $18.80 \pm 10.42$. High risk in eating attitudes was found in $12.0 \%$ of all participants. It was observed that mothers who did not breastfeed were mostly in high risk group in terms of eating attitude. Conclusion: Mothers who did not breastfeed were mostly in high risk group in terms of eating attitude compared to breastfeeding mothers. It is of great importance that healthcare professionals organize trainings for increasing the general level of knowledge of mothers and provide healthy living and breastfeeding counseling.
\end{abstract}

\section{Hosted file}

manuscript.pdf available at https://authorea.com/users/378525/articles/494993-is-therea-relationship-between-breastfeeding-status-and-life-style-changes-eating-behaviorsattitudes-and-orthorexia-nervosa-tendencies-of-mothers-a-web-based-study 